\title{
THE INFLUENCE OF LIFE STRESS, COMPETITIVE TRAIT AMXIETY, AND SLEEP DISTURBANCE ON INJURY SUSCEPTIBLLITY IN FOOTBALL
}

\author{
Umut Dikmen ${ }^{A, B, C, D, E}$ \\ Institute of Exercise Training and Sport Informatics, German Sport University Cologne, Cologne, NRW, Germany \\ ORCID: 0000-0002-3005-6174 | e-mail:Umutd08@gmail.com
}

\author{
Sebastian Schwab', B, C, D, E \\ Institute of Exercise Training and Sport Informatics, German Sport University Cologne, Cologne, NRW, Germany

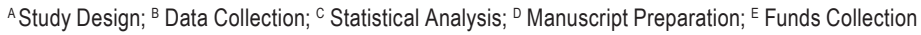

\begin{abstract}
Ahstract Aim: The purpose of the current study was to analyse the effect of life stress, competitive trait anxiety and sleep disturbance on injury susceptibility in football players.

Methods: Participants were 67 male football players from different teams in Cologne ranging in age from 18 to 25 years $(M=21.09$ years; $S D=2.69)$. Participants filled out four questionnaires: The Holmes-Rahe life stress scale, the sport competition anxiety test (SCAT), the Pittsburgh Sleep Quality Index (PSQI), and the Oslo Sports Trauma Research Centre (OSTRC) questionnaire on health problems.

Results: Results suggest that while life stress may increase the injury susceptibility, competitive trait anxiety, and sleep disturbance have no effect on injury susceptibility. Concerning this descriptive data, 53.7\% (36/67) of the players stayed away from the football field for at least one week, and about 23.8\% (16/67) of them did not have any injury during this four months' period.

Conclusion: Our findings suggest that high life stress levels caused athletic injury; for these reasons the psychological dimension should be considered and adapted in the training. Although we found no significant correlation between competitive trait anxiety, and sleep disturbance on injury susceptibility, longitudinal studies are required to assess the effect of life stress, anxiety, and sleep disturbance on injury susceptibility.
\end{abstract}

Key words psychological predictors, sleep, sport injury

\section{Introduction}

There are many definitions of injury in scientific resources. The most accepted injury definition according to Fuller et al. (2006) is "any physical complaint sustained by a player that results from a football match or football training, irrespective of the need for medical attention or time loss from football activities" (Fuller et al., 2006, p. 193). Injuries can be collected under two main titles, namely severity of injuries, and existence mechanism of injuries. Injury severities are classified into four categories: slight (absence from practise between one to three days), minor (absence from practise for more than three days but for less than one week), moderate (absence from 
training or matches for more than one week but less than one month), and major (absence from practise more than one month) (Hägglund, Walden, Ekstrand, 2005a), existence mechanism of injuries are collected under two main subtitles like overuse and traumatic injuries (Hägglund, Walden, Ekstrand, 2005b). Overuse injury means that players develop musculoskeletal pain without any known trauma or complication (e.g., tendinosis, shin splints, stress fractures, etc.), in spite of that, if the injury was caused by a single identifiable event, it was categorized as traumatic injury (Hägglund, Walden, Ekstrand, 2005a). Previous studies showed that traumatic injuries are seen more frequent than overuse injuries (Poulsen, Freund, Madsen, Sandvej, 1991; Brito et al., 2012), for this reason, understanding risk factors, and injury mechanisms are essential to develop effective preventive approaches against football injuries. In 1994, Meeuwisse created a multifactorial model to evaluate risk factors, and causation for sport injuries (Meeuwisse, 1994). In this model, a risk factor is defined as a factor related to the injury. According to the author, risk factors of athletic injuries are classified as internal and external or as intrinsic and extrinsic. Usually, there is just one difference between intrinsic (internal) and extrinsic (external) injury risk factors, where intrinsic risk factors refer to player specific factors, which are individual physical and psychosocial characteristics like the player's age, playing position, strength and flexibility, external injury risk factors can be defined as the factors which are dependent on the environmental conditions like equipment, weather, field conditions, surface types, rules etc. (Murphy, Connolly, Beynnon, 2002; Lysens et al., 1984; Meeuwisse, Bahr, 2009). Sleep disturbance and stress are two intrinsic injury risk factors which humanity has had to cope with since coming into existence. Stress is a highly complex structure consisting of many different factors. In their work, Andersen and Williams (1988) published a schema showing the effects of stress on players' injuries (Andersen, Williams, 1988). According to this schema, factors such as competitive trait anxiety, life stress, motivation, daily hassles,or previous injuries are characterized by a stress response and the risk of injury is increased or decreased according to this stress response. Like stress, sleep disturbance is another process that affects many other systems in the body (Medic, Wille, Hemels, 2017). It is concluded that sleep disturbance has an effect on injuries but this issue needs to be supported by further studies (Milewski et al., 2014). In the light of this information, in order to expand knowledge about relationships between some psychological injury risk factors and injury susceptibility, the aim of this current study is to test the effects of life stress, competitive trait anxiety, and sleep disturbance on injury susceptibility in football players.

\section{Methods}

\section{Study design}

At the beginning, 73 football players of two local clubs in Cologne participated in this study. Players who were injured during the study were included but players who had already injuries before the study period, who left their club during the study period, who joined to the club after 01.08 .2019 , and who had a job or a daily accident (e.g., vehicle accidents, falling from heights or slipping) were not included in the study. All injuries were recorded by team a of physiotherapists. Six players were excluded because they did not meet the study criteria. 67 male football players (Goalkeepers not included) took part voluntarily in this experiment in the season. The players had three training sessions a week (on the pitch) and, in addition to weekly normal training sessions, they played one game at the end of the week. Written informed consent was obtained from every participant before commencing the experiment. The analysed data included level of formal education, age, height, working hours and training time. The mean age of players was $21.09 \pm 2.69$, an average height of $181 \mathrm{~cm} \pm 6.111$, a training time of approximately $8 \pm 3.464$ hours, and working time of $15 \pm 16.385$ hours a week. The study was carried out in accordance with the 
Helsinki Declaration of 1975 and was approved by the Institutional Review Board of the local university. To analyse the effects of life stress, competitive trait anxiety, and sleep disturbance on injury susceptibility the last four months of each player were considered (August-November 2019).

\section{Data collection}

\section{Holmes-Rahe Life Stress Scale}

Holmes-Rahe life stress scale is used to measure life stress level (Noone, 2017) The scale consists of 43 items. Each item has different score for stress, more marked items mean a higher score. The higher score, the more likely the player would become ill. After the assessment finished, the results are classified in three categories. If the score is $\leq 150$, players have low risk of illness, scores between 151 and 299 are moderate risk of illness with $50 \%$ chances and if the score is $\geq 300$, there is high $(80 \%)$ chance of getting ill. Gerst et al. (1978) tested the reliability of the Holmes-Rahe life stress scale, and found that rank ordering remained extremely consistent both for healthy adults $(r=0.96-0.89)$ and patients ( $r=0.91$ to 0.70$)$ (Gerst, Grant, Yager, Sweetwood, 1978).

Sport Competition Anxiety Test (SCAT)

SCAT is used to measure competition trait anxiety (Brand, Hanekom, Scheepers, 1988). The scale consists of 15 statements, the statements were answered on a three-point scale (often, sometimes, hardly ever) and a summary score ranging from 10 (low competitive trait anxiety) to 30 (high competitive trait anxiety). A score of less than 17 indicates a low level of anxiety, 17 to 24 an average level of anxiety, and more than 24 a high level of anxiety. The test-retest reliability of the SCAT has been documented to range from $r=0.73-0.88$ and an internal consistency or $r=0.95-0.97$ (Martens, Vealey, Burton, 1990).

Pittsburgh Sleep Quality Index (PSQI)

PSQI is used to measure sleep disturbance (Buysse, Reynolds, Monk, Berman, Kupfer, 1988) PSQI consists of 19 self-rated questions and 5 questions rated by bed partner. Only self-rated questions are included in the scoring. The 19 self-rated items are grouped into seven component scores, each weighted equally on a 0-3 scale. The seven component scores are then summed to yield a global PSQI score, which has a range of $0-21$; higher scores indicate worse sleep quality. The overall PSQI global score correlation coefficient for test - retest reliability is 0.87 (Backhaus, Junghanns, Broocks, Dieter, Hohagen, 2002).

Oslo Sports Trauma Research Centre Questionnaire (OSTRC)

OSTRC is used to measure players' injuries (Clarsen, Ronsen, Myklebust, Florens, Bahr, 2012). Using this scale all types of health problems in sport can be evaluated; acute injuries, overuse injuries and illnesses can be documented sensitively and validly. Cronbach's a value of OSTRC is 0.92 , this questionnaire has an interclass correlation coefficient 0.91 (Hirschmüller et al., 2017).

All these questionnaires were translated into German and the responsibility for professional conduct during testing was assumed by a trained expert.

\section{Statistical Methods}

Data were statistically analysed using SPSS version 25 . The significance level was set at $p<0.05$. Descriptive data is generally presented for quantitative variables (e.g., age, height, working hours, training time) as mean values with $S D$ or $95 \% \mathrm{Cl}$. The relationships between groups were tested by multiple linear regression analysis, using the 
backward elimination method. Multiple linear regression is a statistical technique that uses several independent variables (life stress, competitive trait anxiety and sleep disturbance) to predict the outcome of a dependent variable (injury susceptibility).

\section{Results}

\section{Injury severity and anatomical location of Injuries}

As shown in Table 1, 51 injuries were reported, 16 players did not sustain any injuries during the examination period. Of the 51 injuries, $43.1 \%$ were slight, $27.5 \%$ minor, $7.8 \%$ moderate and $21.6 \%$ of the injuries were major. Concerning this descriptive data, while $53.7 \%$ (36/67) of the players stayed away from the football field for at least one week, about $23.8 \%$ (16/67) of them did not have any injury during this four months' period. Most injuries were located at the lower extremities (96-98\%). The most common locations of injury among players are the knee (39.5\%), the foot/toes (19.7\%), the hip/groin (15.7\%) and the ankle (9.8\%) respectively. Upper extremity injuries were rarely observed in this group of players. Shoulder, lower back, or thoracic spine injuries were not seen, the incidence rate of injuries to the head/face were $1-2 \%$.

Table 1. Injury location and severity in football players

\begin{tabular}{lccccc} 
& Injuries & Slight & Minor & Moderate & Major \\
\hline Head/face/neck & $1(1.8)$ & $1(4.5)$ & - & - & - \\
Hip/groin & $8(15.7)$ & $2(9)$ & $3(21.4)$ & $3(75)$ & - \\
Thigh & $4(7.8)$ & - & $2(14.2)$ & $1(25)$ & $1(9.1)$ \\
Knee & $20(39.5)$ & $6(27.3)$ & $8(57.2)$ & - & $6(54.5)$ \\
Lower leg & $1(1.8)$ & - & $1(7.2)$ & - & - \\
Ankle & $5(9.8)$ & $4(18.2)$ & - & - & $1(9.1)$ \\
Foot/toes & $10(19.7)$ & $8(36.5)$ & - & - & $2(18.2)$ \\
Other & $2(3.9)$ & $1(4.5)$ & - & $4(100)$ & $11(100)$ \\
\hline Total & $51(100)$ & $22(100)$ & $14(100)$ & & $-1)$ \\
\hline
\end{tabular}

Values in parenthesis are percentages. Approximation of the percentages has been made to equal $100 \%$.

\section{Outcome measure}

As a finding of the survey results $14.9 \%$ of the athletes rated their sleep quality as very good, $65.7 \%$ of them rated their sleep quality as fairly good and $19.4 \%$ rated it as bad and very bad. The average sleep quality index score of injured football players was $7.02(S D=1.57)$, uninjured players have $6.90(S D=1.74)$. While the average stress score of the injured players was about $95.15(S D=79)$, the average stress score of the uninjured players was 36.80 $(S D=22.8)$ and finally, the average competitive anxiety test scores of the injured and uninjured players were 16.43 $(S D=3.56), 17.6(S D=4.01)$ respectively (Figure 1$)$. 


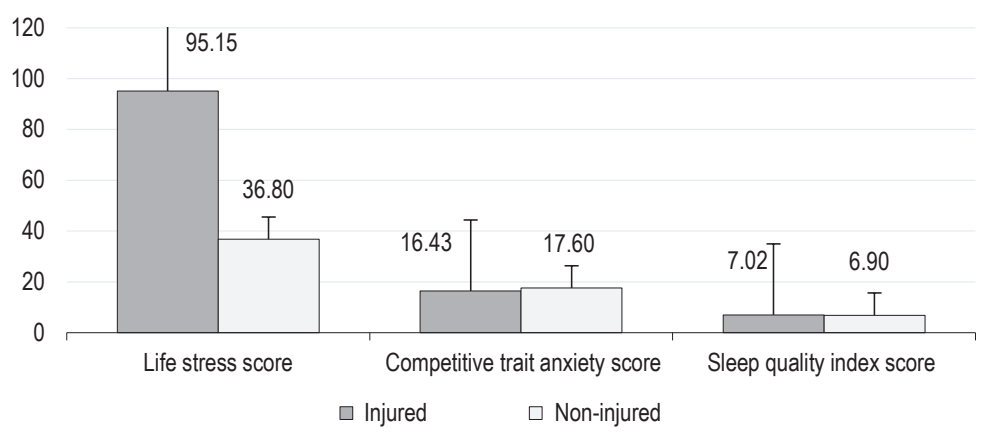

Figure 1. The comparison of life stress score, competitive trait anxiety, sleep duration between injured and uninjured players

The multiple linear regression analysis with backward elimination showed that life stress, competitive trait anxiety, and sleep disturbance could explain $13.3 \%$ of the total variance $\left(R^{2}{ }_{A d j}=0.133, F(3.63)=3.220, p<0.05\right)$. The result of regression analysis indicated that life stress has an influence on injury susceptibility $(p<0.05$; $T=2.731)$, whilst competitive trait anxiety $(p=0.162 ; T=1.414)$, and sleep duration $(p=0.125 ; T=1.554)$ were not significant predictors of injury susceptibility.

\section{Discussion}

The aim of the study was to identify the effect of life stress, competitive trait anxiety, and sleep disturbance on injury susceptibility. The most significant finding in the present study was that there is a positive correlation between life stress and injury susceptibility, in other words, a high stress level causes an increased injury susceptibility among adult male football players. However, there is no correlation between competitive trait anxiety, sleep disturbance and injury susceptibility.

\section{The effect of life stress on foothall injury susceptibility}

While some studies have shown that athletes with high life stress have a high injury risk (Galambos, Terry, Moyle, Locke, 2005; Johnson, Ivarsson, 2009; Petrie, 1992). Ivarsson and Johnson (2010) found that there is no significant relationship between life stress and injury susceptibility (Ivarsson, Johnson, 2010). The current study shows that injured athletes had a significantly higher life stress score in comparison to uninjured players. The average life stress score is 82.09 ( $S D=74.398)$, which means that players have relatively low life stress, despite the players' low life stress score, life stress has an effect on injury susceptibility $(p<0.05)$. This result indicates that life stress has more impact than it would appear. The regression analysis showed that the life stress variable could explain $6 \%$ of the total variance of injury occurrence, which means the life stress variable explains only one of about 17 injuries; this means, injury occurrence could also be influenced by several other internal or external injury factors. It should not be forgotten that there were a few players who had a higher life stress score than others which were proved by the high standard deviation of the stress score of the injured players $(95.15(S D=79))$, from this point of view, the homogeneity of group should be considered by future research. 


\section{The effect of competitive trait anxiety on foothall injury}

Previous studies have found that there is a positive correlation between competitive trait anxiety and sport injuries (Song, Long, Jiao, 2017; Lavallee, Flint, 1996). There is only one study that showed a weak correlation between these two variables (Seidi, Rajabi, Daneshmandi, Fadaee, 2014). In this study, it was observed that competitive trait anxiety has no effect on players' injuries. The average competitive anxiety score was 16.79 $(S D=3.77)$. This score belonged to the first group which shows that their competitive anxiety level is low. When examining the relationship between anxiety and players' injuries, the low anxiety level of athletes limits our deduction while explaining the relationship between the competitive trait anxiety and the athlete's injury. In other words, if it has come up with a clearer explanation, the reason is not known why the athletes did or did not sustain less injury during the study period, whether there was no anxiety effect on athlete injury or whether the anxiety score of our participants was already low. For this reason, the relationship between anxiety and athlete injury should be tested more specifically with a wider group of players and a higher score.

\section{The effect of sleep disturbance on foothall injury}

Stimulation of protein degradation is increased by sleep disturbance, which affects protein synthesis, and the impairment in protein synthesis causes muscular atrophy and decelerates the recovery of athletes (Dattilo et al., 2011), for this reason, sleep plays an important role regarding performance and recovery of athletes (Bonnar, Bartel, Kakoschke, Lang, 2018). The average nocturnal sleep duration is 6.7 hours during the weekdays and on weekends is 7.4 hours (Goel, Rao, Durmer, Dinges, 2009). There are some studies, which have shown a positive correlation between sleep disturbance and sport injury (Gao, Dwivedi, Milewski, Cruz, 2019; Milewski et al., 2014). In the current study, sleep quality index score is low, it means that players have a good sleep quality. Sleep duration of players is about 7 hours, this is normal for athletes aged between 18 and 25. Although the result was found that there is no effect of sleep disturbance on injury susceptibility, this result isn't clear enough. Due to low sleep quality index score and normal sleep duration the effect of sleep disturbance on injury susceptibility is not known, it is also not known whether there was no effect of sleep disturbance on athletes' injury or the sleep quality index score was already low. For this reason, another study would need to be conducted with a wider group of players whose sleep duration and sleep quality index score are different from the average.

\section{Conclusion}

The present study concludes that there is a positive correlation between life stress and athletes' injuries, but competitive trait anxiety and sleep disturbance had no effect on injury susceptibility. It is important to know that the group size and short time period limit the interpretation of the statistical results. Therefore, further studies should be performed with a larger experimental group with long time in order to have more appropriate and interpretable results. In addition to this, in order to achieve more realistic outcomes a study could be designed in the light of previous studies based on one experimental and one control group.

\section{References}

Andersen, M.B., Williams, J.M. (1988). A model of stress and athletic injury: prediction and prevention. Journal of Sport \& Exercise Psychology, 10 (3), 294-306. 
Brand, H.J., Hanekom, J.D.M., Scheepers, D. (1988). Internal consistency of the sport competition anxiety test. Perceptual and Motor Skills, 67 (2), 441-442.

Backhaus, J., Junghanns, K., Broocks, A., Dieter, R., Hohagen, F. (2002). Test-retest reliability and validity of the Pittsburgh Sleep Quality Index in primary insomnia. Journal of Psychosomatic Research, 53 (3), 737-740.

Bonnar, D., Bartel, K., Kakoschke, N., Lang, C. (2018). Sleep interventions designed to improve athletic performance and recovery: A systematic review of current approaches. Springer International Publishing. DOI: 10.1007/s40279-017-0832-x.

Brito, J., Malina, R.M., Massada, J.L., Soares, J.M., Krustrup, P., Rebelo, A. (2012). Injuries in Portuguese youth soccer players during training and match play. Journal of Athletic Training, 47 (2), 191-197. DOI: 10.4085/1062-6050-47.2.191.

Buysse, D.J., Reynolds, C.F., Monk, T.H., Berman, S.R., Kupfer, D.J. (1988). The Pittsburg sleep quality index: A new instrument for psychiatric practice and research. Elsevier, 28 (2), 193-213.

Clarsen, B., Ronsen, O., Myklebust, G., Florens, T.W., Bahr, R. (2012). The Oslo sports trauma research center questionnaire on health problems: a new approach to prospective monitoring of illness and injury in elite athletes. Br. J. Sports Med., 48 (9), 754-760. DOI: 10.1136/bjsports-2012-092087.

Dattilo, M., Antunes, H.K.M., Medeiros, A., Neco, M.M., Souza, H.S., Tufik, S., De Mello, M.T. (2011). Sleep and muscle recovery: Endocrinological and molecular basis for a new and promising hypothesis. Medical Hypothesis, 77 (2), 220-222. DOI: 10.1016/j. mehy.2011.04.017.

Fuller, C.W., Ekstrand J., Junge A., Andersen, T.E., Bahr, R., Dvorak J., Hägglund, M, McCrory, P., Meeuwisse, W.H. (2006). Consensus statement on injury definitions and data collection procedures in studies of football (soccer) injuries. Br J Sports Med., 40 (3): 193-201. DOI: 10.1136/bjsm.2005.025270.

Galambos, S.A., Terry, P.C., Moyle, G.M., Locke, S.A. (2005). Psychological predictors of injury among elite athletes. British Journal Sports Medicine, 39 (6), 351-354. DOI: 10.1093/occmed/kqx099.

Gao, B., Dwivedi, S., Milewski, D.M., Cruz, A.I. (2019). Lack of sleep and sports injuries in adolescents: A systematic review and metaanalysis. J. Pediatr. Orthop., 39 (5), 324-333. DOI: 10.1097/BPO.0000000000001306.

Gerst, M.S., Grant, I., Yager, J., Sweetwood, H. (1978). The reliability of the social readjustment rating scale: moderate and long-term stability. Journal of Psychosomatic Research, 22, 519-623.

Goel, N., Rao, H., Durmer, J.S., Dinges, D.F. (2009). Neurocognitive consequences of sleep deprivation. Semin Neurol, 29 (4), 320-339. DOI: 10.1055/s-0029-1237117.

Hirschmüller, A., Steffen, K., Fassbender, K., Clarsen, B., Leonhard, R., Konstantinidis, L., Südkamp, N.P., Kubosch, E.J. (2017). German translation and content validation of the OSTRC questionnaire an overuse injuries and health problems. Br. J. Sports Med., 51 (4), 260-264. DOI: 10.1136/bjsports-2016-096669.

Hägglund, M., Walden, M., Ekstrand, J. (2005a). Injury incidence and distribution in elite football-a prospective study of the Danish and the Swedish top divisions. Scandinavian Journal of Medicine and Science in Sports, 15 (1), 21-28. DOI: 10.1111/j.1600-0838.2004.00395.x.

Hägglund, M., Walden, M., Ekstrand, J. (2005b). UEFA Champions League study: a prospective study of injuries in professional football during the 2001-2002 season. British Journal of Sports Medicine, 39 (8), 542-546. DOI: 10.1136/bjsm.2004.014571.

Ivarsson, A., Johnson, U. (2010). Psychological factors as predictors of injuries among senior soccer players. A prospective study. Journal of Sports Science and Medicine, 9 (2), 347-352. DOI: 10.1111/j.1600-0838.2009.01057.x.

Johnson, U., Ivarsson, A. (2009). Psychological predictors of sport injuries among junior soccer players. Scandinavian Journal of Medicine and Science in Sports, 21 (1), 129-136.

Lavallee, L., Flint, F. (1996). The relationship of stress, competitive anxiety, mood state and social support to athletic injury. York University School of Physical Education, 31 (4), 296-299.

Lysens, R., Steverlynck, A., Van den Auweele, Y., Lefevre, J., Renson, L., Claessens, A. (1984). Sports Medicine. The Predictability of Sports Injuries. Springer, Berlin.

Martens, R., Vealey, R.S., Burton, D. (1990). Competitive anxiety in sport. Champaign, IL: Human Kinetics.

Medic, G., Wille, M., Hemels, M.H. (2017). Short- and long-term health consequences of sleep disruption. Nature and Science of Sleep, 19 (9), 151-161. DOI: 10.2147/NSS.S134864.

Meeuwisse, W.H. (1994). Assessing causation in sport injury: A multifactorial model. Clinical Journal of Sport Medicine, 4, 166-170.

Meeuwisse, W., Bahr, R. (2009). Sports injury prevention. A systematic approach to sports injury prevention. United Kingdom: Wiley-Blackwell.

Noone, P.A. (2017). The Holmes-Rahe stress inventory. Occupational medicine, 67 (7), 581-582. 
Murphy, D.F., Connolly, D.A.J., Beynnon, B.D. (2002). Risk factors for lower extremity injury: a review of the literature. Br. J. Sports Med., 37 (1), 13-29. DOI: 10.1136/bjsm.37.1.13.

Milewski, M.D., Skaggs, D.L., Bishop, G.A., Pace, L., Ibrahim, D.A., Wren, T.A.L., Barzdukas, A. (2014). Chronic lack of sleep is associated with increased sports injuries in adolescent athletes. J. Pediatr. Orthop., 34 (2), 129-133. DOI: 10.1097/BP0.0000000000000151.

Petrie, T.A. (1992). Psychosocial Antecedents of Athletic Injury: The Effects of Life Stress and Social Support on Female Collegiate Gymnasts. Behavioural Medicine, 18 (3), 127-138.

Poulsen, T.D., Freund, K.G., Madsen, F., Sandvej, K. (1991). Injuries in high-skilled and low-skilled soccer: a prospective study. British Journal of Sports Medicine, 25 (3), 151-153. DOI: 10.1136/bjsm.25.3.151.

Seidi, F., Rajabi, S., Daneshmandi, H., Fadaee, E. (2014). The relationship between the competitive-trait anxiety and the rate of sports injuries in Professional soccer players. International Research Journal of Applied and Basic Science, 8 (12), 2210-2213.

Song, Y., Long, X., Jiao, J. (2017). Correlation between competition trait anxiety structure and paroxysmal athletic injuries. Advances in Social Science, Education and Humanities Research, vol.156. DOI: 10.2991/seiem-17.2018.107.

Cite this article aS: Dikmen, U., Schwab, S. (2021). The Influence of Life Stress, Competitive Trait Anxiety, and Sleep Disturbance on Injury Susceptibility in Football. Central European Journal of Sport Sciences and Medicine, 4 (36), 73-80. DOI: 10.18276/ cej.2021.4-07. 